\title{
Should all patients with hypertension be worried about developing severe coronavirus disease 2019 (COVID-19)?
}

\author{
Ramin Hosseinzadeh ${ }^{1}$, Mohammad Ali Sheikh Beig Goharrizi ${ }^{2}$, Mansour Bahardoust ${ }^{1,3^{*}}$, Akbar Ghorbani Alvanegh ${ }^{4}$, \\ Mohammad Reza Ataee ${ }^{5}$, Mehdi Bagheri ${ }^{6}$, Ensiyeh Shabani Navidiyan", Seyed Reza Hosseini Zijoud ${ }^{8}$ and \\ Mohammad Heiat ${ }^{1 *}$
}

\begin{abstract}
Background: Hypertension, the most common comorbidity among coronavirus disease 2019 (COVID-19) patients, is accompanied by worse clinical outcomes, but there is lack of evidence about prognostic factors among COVID19 patients with hypertension. We have come up with some prognostic factors to predict the severity of COVID-19 among hypertensive patients. In addition, epidemiologic, clinical and laboratory differences among COVID-19 patients with and without underlying hypertension were evaluated.

Methods: Medical profiles of 598 COVID-19 cases were analyzed. Patients were divided into two comparative groups according to their positive or negative history of hypertension. Then, epidemiologic, clinical, laboratory and radiological features and also clinical outcomes were compared.

Results: 176 (29.4\%) patients had underlying hypertension. Diabetes was significantly higher in hypertensive group [72 (40.9\%) vs 76 (18\%)] (P-value: 0.001). Cardiovascular and renal disorders were significantly higher in hypertensive patients. ( $P$-value: 0.001 and 0.013 respectively). In COVID-19 patients with hypertension, severe/critical types were significantly higher. [42(23.8\%) vs. $41(9.7 \%)]$, ( $P$-value: 0.012$)$. In the logistic regression model, Body mass index $>25$

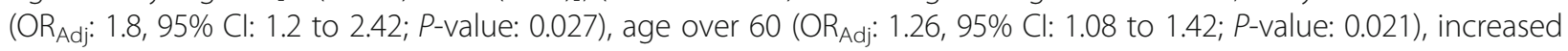
hospitalization period (OR Adj: $_{2.1}$, 95\% Cl: 1.24 to 2.97; $P$-value: 0.013$)$, type 2 diabetes (OR Adj: 2.22 , $95 \%$ Cl: 1.15 to 3.31; P-value: 0.001) and chronic kidney disease (OR $\mathrm{Oddj}_{\text {: }} 1.83,95 \%$ Cl: 1.19 to 2.21; P-value: 0.013$)$ were related with progression of COVID-19.
\end{abstract}

Conclusion: Hypertensive patients with Age >60-year-old, BMl $>25 \mathrm{Kg} / \mathrm{m}^{2}, \mathrm{CVD}$, diabetes and chronic kidney disease are associated with poor outcomes in those with COVID-19 infection.

Keywords: Hypertension, Risk factor, Severe COVID-19

\section{Introduction}

The COVID-19 pandemic has involved millions of people and had thousands of victims globally. To the moment of writing this paper (May 5th, 2020), 4,894,278

\footnotetext{
*Correspondence: Mansourbahari93@gmail.com; Mohamad.heiat@gmail.com 1 Baqiyatallah Research Center for Gastroenterology and Liver Diseases, Baqiyatallah University of Medical Sciences, Tehran, Iran Full list of author information is available at the end of the article
}

cases and 320,189 deaths were reported [1]. COVID-19 infection is caused by severe acute respiratory syndrome corona virus-2 (SARS-CoV-2), a member of coronaviridae family, believed to able to spread to human from reservoirs like bats [2].

Due to their large genome, members of coronaviridae family have a great potential to initiate new epidemics as a result of gene mutation. This family of viruses is

C C The Author(s). 2021 Open Access This article is licensed under a Creative Commons Attribution 4.0 International License, which permits use, sharing, adaptation, distribution and reproduction in any medium or format, as long as you give appropriate credit to the original author(s) and the source, provide a link to the Creative Commons licence, and indicate if changes were made. The images or other third party material in this article are included in the article's Creative Commons licence, unless indicated otherwise in a credit line to the material. If material is not included in the article's Creative Commons licence and your intended use is not permitted by statutory regulation or exceeds the permitted use, you will need to obtain permission directly from the copyright holder. To view a copy of this licence, visit http://creativecommons.org/licenses/by/4.0/ The Creative Commons Public Domain Dedication waiver (http://creativecommons.org/publicdomain/zero/1.0/) applies to the data made available in this article, unless otherwise stated in a credit line to the data. 
morphologically known by a crown like protein spike on their envelope [3].

While common symptoms of COVID-19 infection which are cough, fever, fatigue and myalgia can be seen after about 5 days of incubation period, uncommon symptoms such as dyspnea, chest pain, chest tightness, diarrhea and vomiting can also be seen during the time course of infection [3-12].

The main causes of death in COVID-19 infection are acute respiratory distress syndrome (ARDS), renal and cardiac failure [13]. Global mortality rate of COVID-19 infection is estimated about 6\%(5.7\%) [7].

It is acknowledged that people with comorbidities are at a greater risk of getting infected with SARS-CoV-2 and developing severe disease. Hypertension is the most common comorbidity among COVID-19 patients which is accompanied by higher risk of infection and worse outcomes and prognosis [13-18]. The fact that hypertension is the most common comorbidity in COVID-19 patients is not a great surprise because the frequency and severity of the infection is higher in elderly and hypertension is seen frequently in old individuals and as a result, hypertension can be seen in a lot of COVID-19 cases. However it remains unclear whether uncontrolled blood pressure is a risk factor for getting infected with COVID-19 and developing severe disease or not [18].

A meta-analysis demonstrated that patients with underlying cardiovascular disease like hypertension are more susceptible to MERS-CoV infection [19] and some studies have shown that patients with cardiovascular disease especially hypertension are at a greater risk for getting infected with COVID-19 and developing more severe disease but further investigations are needed in this area [20].

Although hypertension is the most common comorbidity among COVID-19 patients and some studies have shown its association with worse outcomes [13-16, 18], there in not enough data available about prognostic factors among COVID-19 patients with underlying hypertension to predict possible outcomes among them, So in the present study we aimed to evaluate epidemiologic, clinical and laboratory differences between COVID-19 patients with and without underlying hypertension and came up with some prognostic factors to predict the severity of the disease and other possible outcomes among patients with pre-existing hypertension.

\section{Method}

\section{Study design and setting}

This retrospective study was approved by the review board of our institute IR.BMSU.REC.1399. 244 and informed consent was obtained from the patients to use their medical information. In this retrospective analytical study, medical profiles of 598 cases with COVID-19 pneumonia who were admitted to Baqiyatallah Hospital in Tehran - Iran were evaluated. Data collection was done via checklists filled with information extracted from patients' medical profiles. All patients had agreed to share their information to help studying the coronavirus outbreak on admission and filled consent forms. Patients' information including demographic data (age, gender, history of smoking, history of alcohol consumption, history of travel in past 2 weeks, history of contact with COVID-19 patents in past 2 weeks, history of hospital visit in past 2 weeks and history of having underlying disease), clinical and laboratory data (fever, gastrointestinal symptoms, biochemical tests, liver function tests, respiratory tests, blood work, radiological findings and CT-scan) was collected. Information about clinical outcomes (increase in hospitalization period, mortality and need to readmission) was also collected. According to previous data, the median of hospitalization period among COVID-19 patients was 14 days in china and 5 days outside china [21] so, a period more than 14 days was defined as increased hospital stay. Patients with incomplete medical profiles, patients who were not receiving any kind of antihypertensive medications and patients who were receiving any corticosteroids were excluded. Then, patients were divided into two comparative groups according to their positive or negative history of hypertension. According to the guideline for the diagnosis and management of hypertension in adults-2016 [22],Systolic blood pressure $>140 \mathrm{mmhg}$ and diastolic $\mathrm{BP}>90 \mathrm{mmhg}$ were set as hypertension cutoff. Final hypertension diagnosis was made by an internal medicine specialist. All hypertensive patients of this study were receiving antihypertensive medications. Definite diagnosis of COVID19 and differentiating it from other viruses like H1N1, H3N2 and H7N9 influenza, respiratory syncytial virus, parainfluenza virus, adenovirus, SARS-CoV and MERS$\mathrm{CoV}$ was done by RT-PCR test and CT-scan results. Finally, epidemiologic, clinical, laboratory and radiological features and also clinical outcomes were compared between patients with and without hypertension. All COVID-19 patients can be divided into one of the clinical stages described below; mild: minimal clinical symptoms and no pneumonia on imaging; moderate: showing clinical symptoms like fever and respiratory manifestations accompanying pneumonia on imaging; severe; cases with at least one criterion of the following criteria: (1) respiratory rate $\geq 30$ times/minute with shortness of breath; (2) arterial partial pressure of oxygen/fraction of inspiration of oxygen $\leq 300 \mathrm{mmHg}$;(3) finger oxygen saturation $\leq 93 \%$ in the resting state; and (4) lesion progression of more than $50 \%$ in $24-48 \mathrm{~h}$ on the chest imaging. Critical: patients with at least one on the following conditions: (1) respiratory failure requiring mechanical 
ventilation; (2) shock; and (3) failure of other organs, and the need for intensive care unit admission [23, 24].

\section{Statistical analysis}

The collected data was analyzed by SPSS version 22 . Descriptive analysis and central tendency (mean and standard deviation) were used for baseline data. In order to compare quantitative variables in two groups, $\mathrm{T}$ test was used for data with normal distribution and Mann-Whitney $U$ test was used for data without normal distribution. Chi-square test was performed to compare qualitative variables. Logistic regression Multivariate analysis was performed to determine most important risk factors of COVID-19 infection severity in hypertensive patients. Variables with $p<0.10$ in the univariate analysis test were entered into a logistic regression multivariate analysis with the backward selection method. This part's findings were reported as odds ratio (OR) with $95 \%$ confidence interval. $P$-value of $<0.05$ was set as statistical significance cutoff.

\section{Results}

In this study, 598 medical profiles of COVID-19 patients were analyzed. 176(29.4\%) patients were hypertensive and $422(70.6 \%)$ were normotensive. Mean age was $58.21 \pm 22.5$ in hypertensive group and $56.21 \pm 20.2$ in normotensive group ( $P$-value: 0.18$) .115(65.3 \%)$ patients in hypertensive group and $289(68.5 \%)$ patients in normotensive group were men ( $P$-value:0.78). Diabetes was seen more in hypertensive group.72(40.9\%)hypertensive patients and 76(18\%) normotensive ones were diabetic which was statistically significant $(P$-value:0.001). Cardiovascular disease was significantly higher in hypertensive group [63,(35.7\%)] in comparison to normotensive group[44(10.3\%)] ( $P$-value:0.001). Renal disorders were significantly higher in hypertensive group [25(14.3\%)]vs.[33(7.8\%)] respectively (P-value:0.013). Severe/critical types were significantly higher in hypertensive group comparing to normotensive one, [42(23.8\%) vs $41(9.7 \%)]$, ( $P$-value:0.012). No significant difference was seen in other variables (history of exposure to COVID-19 patients in past 2 weeks, smoking, brain stroke, respiratory disease, cancer(P-value $>0.05)$, (Table 1).

\section{Clinical and laboratory features and clinical outcome}

Univariate analysis showed that the number of patients with high fever (> 38.5) were significantly higher in hypertensive group [75(44.3\%)] in comparison to normotensive one [125 (9.6\%)], (P: 0.042). Similar results were observed about Dyspnea; [22(12.5\%) vs. 20(4.5\%)] (P: 0.023).

CT-scan findings showed that unilateral involvement was significantly lower in hypertensive group [25(14.2\%)] in comparison with normotensive group [86(20.3\%)], $(P$ value 0.046$)$. However no significant difference was seen in bilateral pulmonary involvement, multiple mottling and ground glass opacity between study groups $(P>$ 0.05). Other clinical symptoms and laboratory results didn't show significant difference between two groups (Table 2).

Comparison of clinical outcomes of COVID-19 between our study groups showed that $41(22.9 \%)$ of hypertensive and $46(10.9 \%)$ of normotensive patients needed longer hospital stay which was statistically significant $(P$ value: 0.015 ). Mortality and need to readmission showed no significant difference between two groups ( $P$ value $>$ $0.05)$, (Table 2). Cause of death in the current study was severe COVID-19 infection leading to ARDS, cardiac arrest and multi-organ failure.

\section{Prediction of risk factors for severe-critical COVID-19 in patients with and without hypertension}

Generally, 23.8\% of hypertensive patients developed severe/critical COVID-19. In order to determine independent predictive variables of severe COVID-19 among hypertensive patients, all variables with statistical significance in univariate distribution were included in logistic regression multivariate analysis. This innovative approach showed that body mass index $(\mathrm{BMI})>25\left(\mathrm{OR}_{\mathrm{Adj}}\right.$ : 1.8, 95\% CI:1.2 to 2.42; $P$-value: 0.027$)$, age over 60(OR ${ }_{\text {Adj }}: 1.26$, 95\% CI:1.08 to 1.42; P-value: 0.021$)$, increased hospitalization period $\left(\mathrm{OR}_{\mathrm{Adj}}: 2.1,95 \% \mathrm{CI}: 1.24\right.$ to 2.97; P-value: 0.013$)$, type 2 diabetes $\left(\mathrm{OR}_{\mathrm{Ad}}: 2.22,95 \%\right.$ CI:1.15 to 3.31; P-value: 0.001) and chronic kidney disease $\left(\mathrm{OR}_{\mathrm{Adj}}: 1.83,95 \% \mathrm{CI}: 1.19\right.$ to 2.21 ; P-value: 0.013$)$ were the significant independent risk factors of severe COVID-19 in hypertensive patients (Table 3). Notably, after performing the same model on the cases without hypertension, it was revealed that only older age was associated with a higher risk of sever disease among these group participants. Severe/critical COVID-19 infection was significantly higher among hypertensive group. Besides, we showed that None of the other risk factors mentioned above (BMI $>25 \mathrm{Kg} / \mathrm{m} 2$, CVD, diabetes and chronic kidney disease) are statistically significant among normotensive group. As a result, we can mention hypertension as a risk factor to develop severe COVID-19 infection.

\section{Discussion}

In the present study performed on 598 patients with confirmed COVID-19, 176 (29.4\%) patients had underlying hypertension. Using a novel approach, we have showed some important risk factors predictive for developing severe infection among COVID-19 hypertensive patients including Age $>60$-year-old, BMI $>25 \mathrm{Kg} / \mathrm{m}^{2}$, CVD, diabetes and chronic kidney disease. 
Table 1 Comparison of demographic characteristics of patients with COVID-19 in two groups (hypertensive and normotensive patients)

\begin{tabular}{|c|c|c|c|}
\hline Variable & hypertensive (N: 176) & Non-hypertensive (N:422) & $P$-value \\
\hline Age (Year) & $58.21 \pm 22.5$ & $56.15 \pm 20.2$ & 0.18 \\
\hline BMI $\left(\mathrm{kg} / \mathrm{m}^{2}\right)$ & $28.62 \pm 4.6$ & $28.01 \pm 4.3$ & 0.13 \\
\hline Sex (male) & 115(65.3\%) & $289(68.5 \%)$ & 0.78 \\
\hline Education & & & 0.65 \\
\hline$\cdot<$ diploma & 57 (32.4\%) & $111(26.3 \%)$ & \\
\hline$\cdot>$ Diploma & $119(67.6 \%)$ & $311(73.7 \%)$ & \\
\hline Exposure history & $30(17 \%)$ & $191(45.2 \%)$ & 0.45 \\
\hline - Contact with patients & $118(67 \%)$ & $250(59.2 \%)$ & 0.061 \\
\hline - Go hospital & $30(17 \%)$ & $87(20.6 \%)$ & 0.23 \\
\hline - Public transportation & $24(22.5 \%)$ & $118(24.1 \%)$ & 0.64 \\
\hline Comorbidities (positive) & $108(61.3 \%)$ & $249(59 \%)$ & 0.75 \\
\hline Current smoker & $4(2.2 \%)$ & $12(2.8 \%)$ & 0.92 \\
\hline Diabetes & $72(40.9 \%)$ & $76(18 \%)$ & 0.001 \\
\hline CVD & 63(35.7\%) & $44(10.3 \%)$ & 0.001 \\
\hline $\mathrm{Ml}$ & $4(2.3 \%)$ & $2(0.5 \%)$ & 0.061 \\
\hline Lung diseases & $36(20.4 \%)$ & $52(12.3 \%)$ & 0.07 \\
\hline Asthma and Allergy & $31(17.6 \%)$ & $67(15.9 \%)$ & 0.45 \\
\hline Kidney diseases & $25(14.3 \%)$ & $33(7.8 \%)$ & 0.013 \\
\hline Liver diseases & $10(5.7 \%)$ & $22(5.2 \%)$ & 0.47 \\
\hline Cancer & $4(2.3 \%)$ & $8(1.9 \%)$ & 0.68 \\
\hline \multicolumn{4}{|l|}{ Blood Group } \\
\hline$\cdot \mathrm{A}$ & $55(31.3 \%)$ & 139(32.8\%) & 0.21 \\
\hline$\cdot B$ & $45(25.5 \%)$ & $110(26.3 \%)$ & 0.71 \\
\hline$\cdot A B$ & $21(11.9 \%)$ & $60(14.2 \%)$ & 0.52 \\
\hline$\cdot 0$ & $55(31.3 \%)$ & $113(26.7 \%)$ & 0.31 \\
\hline \multicolumn{4}{|c|}{ Clinical type of COVID- 19 infection on admission } \\
\hline Severe/Critical type (\%) & $42(23.8 \%)$ & $41(9.7 \%)$ & 0.012 \\
\hline
\end{tabular}

MI: myocardial infarction, CVD: cardiovascular disease

As it is proven before, hypertension is the most common underlying disorder among COVID-19 patients [25-29]. Shi et al., and Guo et al., reported a high prevalence of hypertension (59.8-63.5\%), among COVID-19 patients which was accompanied by mortality [30, 31]. A study conducted by Lippi et at., reported that hypertension carries higher risk of developing severe COVID-19 [32].

Since hypertension is the most common comorbidity among COVID-19 patients and it has been frequently reported that hypertension increases severity of COVID19 infection $[25,27-29,33]$, a lot of hypertensive people would be worried about ending up with severe COVID19 infection and poor clinical outcomes, So we have done a completely novel study which can show hypertensive patients the most important risk factors to develop severe COVID-19 among them and tell them should they really be worried about developing severe COVID-19 or not.

There are some studies showing that some laboratory parameters are predictors of worse clinical outcomes in COVID-19 patients. Some of these parameters are cardiac biomarkers, pro-inflammatory cytokines and ferritin [34]. Moreover, some other clinical predictors have also been reported in early studies such as, old age, male gender, cardiovascular diseases, respiratory diseases and diabetes to be related with severe COVID-19 [14] but until this moment, there is no data available to specifically show risk factors of developing severe COVID-19 among hypertensive patients.

The reason why hypertensive patients are at a greater risk of severe COVID-19 is unclear. However, a possible theory is that Human pathogenic coronaviruses (severe acute respiratory syndrome coronavirus family; SARS- 
Table 2 Comparison of clinical symptoms, laboratory findings and clinical outcomes of patients with COVID-19 in two groups (hypertensive and normotensive patients)

\begin{tabular}{|c|c|c|c|c|}
\hline Symptoms & Normal range & hypertensive (N: 176) & Non-hypertensive (N:422) & $P$ value \\
\hline Fever & N (\%) & & & 0.042 \\
\hline$\cdot \geq 38.5 \mathrm{c}$ & & $78(44.3 \%)$ & $125(29.6 \%)$ & \\
\hline$\cdot<38.5$ & & $98(45.7 \%)$ & $300(70.4 \%)$ & \\
\hline Cough & N (\%) & $103(58.5 \%)$ & $257(60.9 \%)$ & 0.38 \\
\hline Dysphonia & N (\%) & 105(59.6\%) & $261(61.8 \%)$ & 0.37 \\
\hline Chest pain & N (\%) & $38(21.6 \%)$ & $107(25.3 \%)$ & 0.19 \\
\hline Dizziness & N (\%) & 19(10.7\%) & $56(13.2 \%)$ & 0.18 \\
\hline Headache & N (\%) & $56(31.8 \%)$ & $153(36.2 \%)$ & 0.18 \\
\hline Weakness & N (\%) & $90(51.4 \%)$ & $232(55.1 \%)$ & 0.24 \\
\hline Rhinorrhea & N (\%) & $20(11.3 \%)$ & $41(9.7 \%)$ & 0.3 \\
\hline Myalgia & N (\%) & $62(35.2 \%)$ & $154(36.5 \%)$ & 0.61 \\
\hline Test Sense & N (\%) & 21(11.9\%) & $51(12 \%)$ & 0.91 \\
\hline Shortness of breath & N (\%) & $22(12.5 \%)$ & $20(4.7 \%)$ & 0.023 \\
\hline Diarrhea & N (\%) & $34(19.3 \%)$ & $84(19.9 \%)$ & 0.76 \\
\hline Vomiting & N (\%) & $53(30.2 \%)$ & $136(32.3 \%)$ & 0.23 \\
\hline \multicolumn{5}{|l|}{ Laboratory tests } \\
\hline Leucocytes (× 109/L) & $4-10$ & $7.61 \pm 7.45$ & $6.26 \pm 3.08$ & 0.14 \\
\hline Neutrophils (×109/L) & $2-7$ & $6.28 \pm 0.65$ & $5.23 \pm .065$ & 0.12 \\
\hline Lymphocytes (×109/L) & $0.8-4$ & $2.09 \pm 1.68$ & $2.06 \pm 1.68$ & 0.31 \\
\hline Platelets (×109/L) & $125-450$ & $164.2 \pm 63.1$ & $159.6 \pm 75.2$ & 0.12 \\
\hline Hemoglobin (g/L) & $115-150$ & $15.67 \pm 2.7$ & $14.8 \pm 2.8$ & 0.068 \\
\hline Hematocrit (\%;) & $33.35-50.8$ & $44.15 \pm 3.7$ & $42.1 \pm 4.3$ & 0.23 \\
\hline Albumin (g/L) & $40-55$ & $44.15 \pm 7.8$ & $41.5 \pm 6.5$ & 0.063 \\
\hline Alt(U/L) & $9-50$ & $40.5 \pm 24.6$ & $39.6 \pm 29.2$ & 0.081 \\
\hline Ast(U/L) & $15-40$ & $36.1 \pm 26.2$ & $32.2 \pm 25.1$ & 0.038 \\
\hline Total bilirubin) & $0-26$ & $9.1 \pm 3.1$ & $8.6 \pm 4.2$ & 0.25 \\
\hline Serum sodium (mmol/L) & $137-147$ & $135.6 \pm 15.5$ & $134.1 \pm 18.1$ & 0.71 \\
\hline Serum potassium (mmol/L) & $3.5-5.3$ & $3.41 \pm 2.4$ & $3.31 \pm 2.9$ & 0.77 \\
\hline Glucose (mmol/L) & $70-140$ & $5.99 \pm 2.15$ & $5.01 \pm 1.96$ & 0.62 \\
\hline INR & $0.85-1.15$ & $1.41 \pm 0.17$ & $1.15 \pm 0.13$ & 0.28 \\
\hline $\mathrm{CRP}(\mathrm{mg} / \mathrm{L}) \mathrm{d}$ & $0-10$ & $41.2 \pm 32.1$ & $39.8 \pm 31.2$ & 0.11 \\
\hline Chest $\mathrm{X}$-ray/CT findings & N (\%) & & & \\
\hline • Normal & & 19(10.7\%) & $50(11.8 \%)$ & 0.24 \\
\hline - Unilateral pneumonia & & $25(14.2 \%)$ & $86(20.3 \%)$ & 0.046 \\
\hline - Bilateral pneumonia & & $68(38.6 \%)$ & $156(36.9 \%)$ & 0.12 \\
\hline - Multiple mottling and ground-glass opacity & & $64(36.5 \%)$ & 159(31\%) & 0.071 \\
\hline \multicolumn{5}{|l|}{ Clinical outcome } \\
\hline Increased hospital stays & N (\%) & $41(22.9 \%)$ & $46(10.9 \%)$ & 0.015 \\
\hline Death & N (\%) & $16(9.1 \%)$ & $25(5.9 \%)$ & 0.11 \\
\hline Readmission & N (\%) & $20(11.3 \%)$ & $42(9.9 \%)$ & 0.28 \\
\hline
\end{tabular}

PCR: Polymerase chain reaction, ALT: Alanine aminotransferase AST: Aspartate transaminase, BS: blood sugar, INR: International normalized ratio, CRP: c-reactive protein 
Table 3 Multivariate logistic Regression of Factors Associated with Progression of disease in patients with and without hypertension

\begin{tabular}{|c|c|c|c|c|c|c|}
\hline \multirow[t]{3}{*}{ Variable } & \multicolumn{6}{|l|}{ group } \\
\hline & \multicolumn{3}{|c|}{ Non-hypertensive } & \multicolumn{3}{|c|}{ Non-hypertensive } \\
\hline & OR Adj & $95 \% \mathrm{Cl}$ & $P$ value & OR Adj & $95 \% \mathrm{Cl}$ & $P$ value \\
\hline Age>60year-old & 1.26 & $1.08-1.46$ & 0.021 & 1.06 & 011. -2.08 & 0.044 \\
\hline $\mathrm{BMI}>25(\mathrm{~kg} / \mathrm{m} 2)$ & 1.8 & $1.02-2.42$ & 0.027 & 1.34 & $0.88-1.89$ & 0.21 \\
\hline Increased hospital stays (positive) & 2.1 & $1.24-2.97$ & 0.013 & 1.48 & $0.36-2.61$ & 0.28 \\
\hline CVD (positive) & 3.3 & $1.3-5.4$ & 0.001 & 2.8 & $0.84-4.78$ & 0.058 \\
\hline Diabetes (positive) & 2.22 & $1.15-3.31$ & 0.001 & 1.24 & $0.59-1.92$ & 0.28 \\
\hline Kidney daisies (positive) & 1.83 & $1.19-2.21$ & 0.013 & 1.22 & $0.66-1.81$ & 0.052 \\
\hline
\end{tabular}

OR Adj: Odds Ratio Adjusted; 95\%Cl: 95\% Confidence Interval

CoV, MERS-CoV and SARS-CoV-2), bind to their target cells through Angiotensin Converting Enzyme 2 (ACE2), which is expressed by epithelial cells of the lung, intestine, kidney, and blood vessels [23]. Notably, the underlying hypertension in COVID-19 patients is often treated with angiotensin-converting enzyme inhibitors (ACEI) and angiotensin receptor blockers (ARBs). Controlling hypertension with ACE inhibitors and ARBs, results in an up regulation of ACE2 [35]. Consequently, the increased expression of ACE2 might facilitate COVID-19 infection.

Our novel study reveals predictive factors for developing severe COVID-19 that can be used by physicians to identify high risk hypertensive COVID-19 cases and determine appropriate treatment approach to achieve best possible clinical outcomes.

The only limitation of our study was its retrospective design in which some terms were out of researcher's control. Further studies in bigger populations and other races are needed to confirm whether our novel predictive factors for developing severe COVID-19 in hypertensive patients can be true about other populations and races or not. Also, all hypertensive patients of this study were receiving anti-hypertensive medications but the data of the exact class of anti-hypertensive medication was not collected.

\section{Conclusion}

Although hypertensive patients are at increased risk of developing more severe COVID-19 compared to normotensives, here we came up with some predictive factors to identify patients with poor outcomes in those with COVID-19 infection which are: Age $>60$-year-old, $\mathrm{BMI}>25 \mathrm{Kg} / \mathrm{m}^{2}, \mathrm{CVD}$, diabetes and chronic kidney disorders.

\section{Abbreviations}

COVD-19: Coronavirus disease 2019; SARS-CoV-2: Severe acute respiratory syndrome corona virus-2; ACE2: Angiotensin Converting Enzyme 2; ACEl: Angiotensin-converting enzyme inhibitors; ARBs: Angiotensin receptor blockers; OR Adj: Odds Ratio Adjusted

\section{Acknowledgments}

Herby, the authors would like to express gratitude to the guidance and advice from the "Clinical Research Development Unit of Baqiyatallah Hospital, Tehran, Iran".

\section{Authors' contributions}

Conception and design: R H, M N, M A G, M H. Analysis and interpretation of data: MB. Data collection: A G A, M R E, E S N, SR Z. Authors participate in drafting the article or revising: $\mathrm{R} \mathrm{H}, \mathrm{M} \mathrm{N}, \mathrm{M} \mathrm{A} \mathrm{G}, \mathrm{M} \mathrm{H}$. I attest to the fact that all authors listed on the title page have read and approved the manuscript, attest to the validity and legitimacy of the data and its interpretation, and agree to its submission to "Clinical Hypertension" for an evaluation and reviewing for maybe publishing.

\section{Funding}

We have no funding resource for this study.

\section{Availability of data and materials}

On presumable requests, the data sets used for analysis during the current study are available from the corresponding author.

\section{Ethics approval and consent to participate}

This retrospective study was approved by the review board of our institute IR.BMSU.REC.1399. 244 and informed consent was obtained from the patients to use their medical information.

\section{Consent for publication}

Not applicable.

\section{Competing interests}

The authors have no conflicts of interest to declare for this study.

\section{Author details}

${ }^{1}$ Baqiyatallah Research Center for Gastroenterology and Liver Diseases, Baqiyatallah University of Medical Sciences, Tehran, Iran. ${ }^{2}$ Atherosclerosis Research Center, Baqiyatallah University of Medical Sciences, Tehran, Iran. ${ }^{3}$ Department of Epidemiology, School of Public Health, Shahid Beheshti University of Medical Sciences, Tehran, Iran. ${ }^{4}$ Human Genetics Research Center, Baqiyatallah University of Medical Sciences, Tehran, Iran. ${ }^{5}$ Applied Microbiology Research Center, Systems Biology and Poisonings Institute, Baqiyatallah University of Medical Sciences, Tehran, Iran. ${ }^{6}$ Chemical Injuries Research Center, Systems Biology and Poisonings Institute, Baqiyatallah University of Medical Sciences, Tehran, Iran. ${ }^{7}$ Student Research Committee, Baqiyatallah University of Medical Sciences, Tehran, Iran. ${ }^{8}$ Clinical Research Development Unit, Imam Hossein Hospital, Shahid Beheshti University of Medical Sciences, Tehran, Iran.

Received: 20 August 2020 Accepted: 8 January 2021

Published online: 15 January 2021

\section{References}

1. Anon. Coronavirus Update (Live): 4, 852 Cases and 303,584 Deaths from COVID-19 Virus Pandemic - Worldometer. Available at: https://www. worldometers.info/coronavirus/. Accessed May 15,2020. 
2. Paules $\mathrm{Cl}$, Marston $\mathrm{HD}$, Fauci $\mathrm{AS}$. Coronavirus infections-more than just the common cold. Jama. 2020;323(8):707-8.

3. Lum LHW, Tambyah PA. Outbreak of COVID-19-an urgent need for good science to silence our fears? Singap Med J. 2020;61 (2):55.

4. Chen N, et al. Epidemiological and clinical characteristics of 99 cases of 2019 novel coronavirus pneumonia in Wuhan, China: a descriptive study. Lancet. 2020;395(10223):507-13.

5. Qian, G.-Q., et al., Epidemiologic and clinical characteristics of 91 hospitalized patients with COVID-19 in Zhejiang, China: a retrospective, multi-Centre case series. QJM: An International Journal of Medicine, 2020.

6. Xu Y-H, et al. Clinical and computed tomographic imaging features of novel coronavirus pneumonia caused by SARS-CoV-2. J Infect. 2020.

7. Baud D, et al. Real estimates of mortality following COVID-19 infection. Lancet Infect Dis. 2020.

8. Jiang X, Rayner S, Luo MÄ. Does SARS-CoV-2 has a longer incubation period than SARS and MERS? J Med Virol. 2020

9. Guan W-J, et al. Clinical characteristics of coronavirus disease 2019 In China. New England journal of medicine. 2020;382(18):1708-20.

10. Liu K, et al. Clinical characteristics of novel coronavirus cases in tertiary hospitals in Hubei Province. Chin Med J. 2020.

11. Huang, Y., et al., Clinical characteristics of laboratory confirmed positive cases of SARS-CoV-2 infection in Wuhan, China: A retrospective single center analysis. Travel medicine and infectious disease, 2020.

12. Chen T, et al. Clinical characteristics of 113 deceased patients with coronavirus disease 2019: retrospective study. Bmj. 2020;368.

13. Emami A, et al. Prevalence of underlying diseases in hospitalized patients with COVID-19: a systematic review and meta-analysis. Archives of academic emergency medicine. 2020:8(1).

14. Zhou F, et al. Clinical course and risk factors for mortality of adult inpatients with COVID-19 in Wuhan, China: a retrospective cohort study. Lancet. 2020.

15. Grasselli G, et al. Baseline characteristics and outcomes of 1591 patients infected with SARS-CoV-2 admitted to ICUs of the Lombardy region, Italy. Jama. 2020;323(16):1574-81.

16. Fang, L., G. Karakiulakis, and M. Roth, Are patients with hypertension and diabetes mellitus at increased risk for COVID-19 infection? The Lancet. Respiratory Medicine, 2020.

17. Li B, et al. Prevalence and impact of cardiovascular metabolic diseases on COVID-19 in China. Clin Res Cardiol. 2020:1-8.

18. Schiffrin, E.L., et al., Hypertension and COVID-19. 2020, Oxford University Press US.

19. Badawi A, Ryoo SG. Prevalence of comorbidities in the Middle East respiratory syndrome coronavirus (MERS-CoV): a systematic review and meta-analysis. Int J Infect Dis. 2016:49:129-33.

20. Zheng Y-Y, et al. COVID-19 and the cardiovascular system. Nat Rev Cardiol. 2020;17(5):259-60.

21. Rees, E.M., et al., COVID-19 length of hospital stay: a systematic review and data synthesis. 2020

22. Gabb GM, et al. Guideline for the diagnosis and management of hypertension in adults—2016. Med J Aust. 2016;205(2):85-9.

23. Wan $Y$, et al. Receptor recognition by the novel coronavirus from Wuhan: an analysis based on decade-long structural studies of SARS coronavirus. J Virol. 2020:94(7).

24. Zu ZY, et al. Coronavirus disease 2019 (COVID-19): a perspective from China. Radiology. 2020:200490.

25. Xiang, T.X., J.M. Liu, and F. Xu, Analysis of clinical characteristics of 49 patientswith novel coronavirus pneumonia in Jiangxi Province. Chinese J Respir Crit Care Med, 2020.

26. Wang, Z., et al., Clinical features of 69 cases with coronavirus disease 2019 in Wuhan, China. Clinical Infectious Diseases, 2020.

27. Qin, C., et al., Dysregulation of immune response in patients with COVID-19 in Wuhan, China. Clinical Infectious Diseases, 2020.

28. Liu W, et al. Analysis of factors associated with disease outcomes in hospitalized patients with 2019 novel coronavirus disease. Chin Med J. 2020.

29. Chen C, et al. Analysis of myocardial injury in patients with COVID-19 and association between concomitant cardiovascular diseases and severity of COVID-19. Zhonghua xin xue guan bing za zhi. 2020;48:E008.

30. Shi, S., et al., Assoeciation of cardiac injury with mortality in hospitalized patients with COVID-19 in Wuhan, China. JAMA cardiology, 2020.

31. Guo, T., Y. Fan, and M. Chen, Cardiovascular implications of fatal outcomes of patients with coronavirus disease 2019 (COVID-19) JAMA Cardiol. doi: https:// doi.org/10.1001/jamacardio. 2020.1017. Published Online First, 2020. 27.
32. Lippi G, Wong J, Henry BM. Hypertension and its severity or mortality in coronavirus disease 2019 (COVID-19): a pooled analysis. Pol Arch Intern Med. 2020;130:304-9.

33. Wang D, et al. Clinical characteristics of 138 hospitalized patients with 2019 novel coronavirus-infected pneumonia in Wuhan, China. Jama. 2020;323(11): 1061-9.

34. Henry, B.M., et al., Hematologic, biochemical and immune biomarker abnormalities associated with severe illness and mortality in coronavirus disease 2019 (COVID-19): a meta-analysis. Clinical Chemistry and Laboratory Medicine (CCLM), 2020. 1 (ahead-of-print).

35. Li XC, Zhang J, Zhuo JL. The vasoprotective axes of the renin-angiotensin system: physiological relevance and therapeutic implications in cardiovascular, hypertensive and kidney diseases. Pharmacol Res. 2017;125: 21-38.

\section{Publisher's Note}

Springer Nature remains neutral with regard to jurisdictional claims in published maps and institutional affiliations.
Ready to submit your research? Choose BMC and benefit from:

- fast, convenient online submission

- thorough peer review by experienced researchers in your field

- rapid publication on acceptance

- support for research data, including large and complex data types

- gold Open Access which fosters wider collaboration and increased citations

- maximum visibility for your research: over $100 \mathrm{M}$ website views per year

At BMC, research is always in progress.

Learn more biomedcentral.com/submissions 